\title{
A case of intramuscular myxoma presenting as a swollen shoulder: a case report
}

\author{
Bahattin Kemah ${ }^{*}$, Mehmet Salih Soylemez ${ }^{1}$, Bahar Ceyran², Serkan Şenol ${ }^{2}$, Serhat Mutlu ${ }^{3}$ and Korhan Özkan ${ }^{4}$
}

\begin{abstract}
Introduction: Intramuscular myxoma is a rare benign mesenchymal tumor. Myxomas most commonly occur in the heart. They may occur less frequently in aponeurotic tissues, bone, genitourinary tract, subcutaneous tissue and skin.

Case presentation: The case described here is a 44-year-old Turkish woman who presented with the complaint of a swelling in her right shoulder. A preoperative magnetic resonance imaging revealed a lobular contoured mass lesion in her deltoid muscle. The mass was marginally excised and pathology revealed intramuscular myxoma.

Conclusion: Intramuscular myxoma of the deltoid muscle is a very rare benign tumor. In the differential diagnosis, reactive lesions, myxoid nodular fasciitis and low -grade myxoid sarcomas should be kept in mind, upon which the treatment should be planned.
\end{abstract}

Keywords: Benign tumor, Deltoid muscle, Intramuscular myxoma, Myxoma

\section{Introduction}

Myxomas have been described as a true neoplasm of low-vascularity composed of undifferentiated satellite cells embedded in myxoid stroma containing collagen and reticular fibers [1]. Myxoma is the most common intracardiac (atrial) tumor [2]. Extracardiac myxomas may occur in aponeurotic tissues, bone, genitourinary tract, skin, retroperitoneum, intestine, pharynx, joints and skeletal muscles [1]. Osseous myxomas have been reported in the jawbones and calcaneum [3]. Extracardiac myxomas are benign tumors with a slow growth rate and low mitotic activity, which are surrounded by skeletal muscles; they usually present in the 4th to 6th decades of life in women [4-7].

Intramuscular myxoma usually occurs as an isolated lesion. The first case of intramuscular myxoma was described in 1965 [8]. Intramuscular myxoma rarely occurs as multiple lesions associated with fibrous dysplasia of the bone (Mazabraud syndrome) or as a part of McCuneAlbright syndrome [2,9-13].

Here we report a case of a 44-year-old woman with myxoma located in her right deltoid muscle and aim to

\footnotetext{
* Correspondence: bahattinkemah.md@gmail.com

'Orthopaedics and Traumatology Department, I. Medeniyet University

Göztepe Training and Research Hospital, İstanbul, Turkey

Full list of author information is available at the end of the article
}

discuss intramuscular myxomas in the light of clinical, radiological and pathological data.

\section{Case presentation}

A 44-year-old Turkish woman presented to our clinic with the complaint of a 3-year history of a slow growing palpable mass in her right shoulder. She had no other documented or reported condition.

Her physical examination revealed a palpable, mobile, painless, partially fluctuating mass, $5 \times 5 \mathrm{~cm}$ in size, in her deltoid muscle, extending to the lower lateral part of her right shoulder and proximal lateral part of her right arm.

Magnetic resonance imaging (MRI) revealed a lobular contoured mass lesion, cystic in nature and measuring $34 \times 23 \times 37 \mathrm{~mm}$ at its largest that was located caudal to the lateral compartment of her deltoid muscle and an interstitial edema in the adjacent deltoid muscle (Figure 1). A complete blood count, biochemical and other laboratory tests revealed normal values.

During her surgical operation, the mass was approached via a longitudinal incision over the mass in the deltoid area of her right shoulder, sensory neural branches of the axillary nerve were preserved, and the encapsulated gelatinous mass $4 \times 5 \mathrm{~cm}$ in size was easily separated from the muscle tissue and then excised. A 


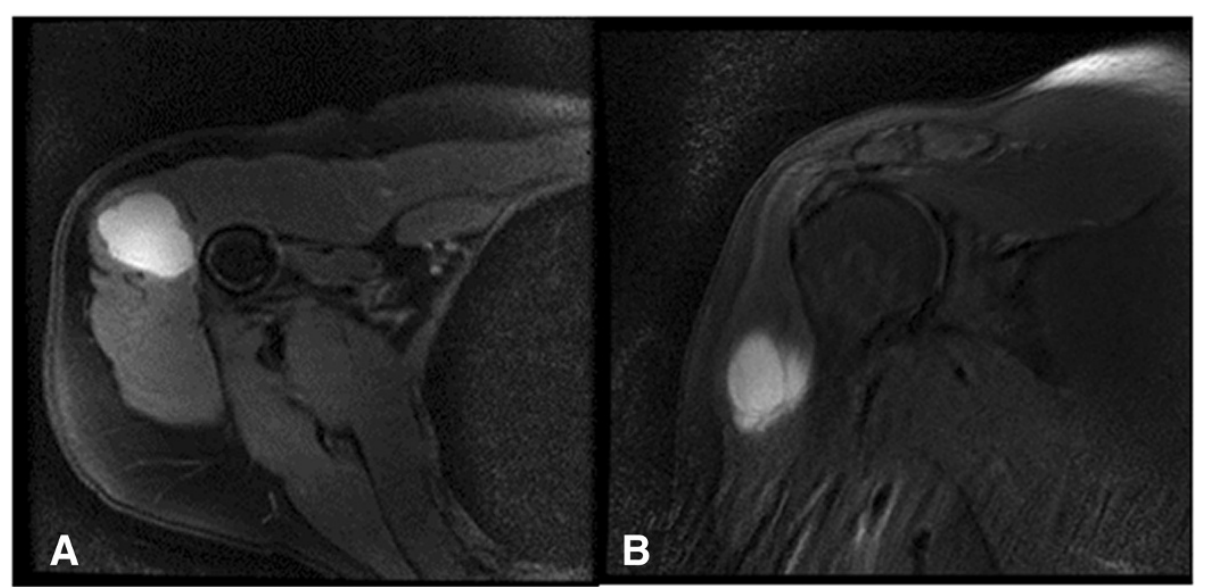

Figure 1 Appearance of the mass on T2-weighted magnetic resonance imaging sections. A) In axial section; B) in coronal section.

macroscopic pathological examination of the mass revealed a nodular lesion cream-beige in color, $2.5 \times 2.5 \times 3 \mathrm{~cm}$ in size and capsular in appearance that was adjacent to the deltoid muscle. The sectioned surface of the mass was pink-beige in color and solid bright myxoid in appearance. The surgical margin was tumor-free.

A microscopic examination showed that the mass consisted of a small number of spindle or stellate cells, a small number of vessels, thin collagen fibers and a small number of loose reticular fibers embedded in an abundant myxoid stroma (Figure 2). The cells had a small, pyknotic slightly hyperchromatic nucleus and scanty cytoplasm. Some presented multiple stellate-shaped cytoplasmic

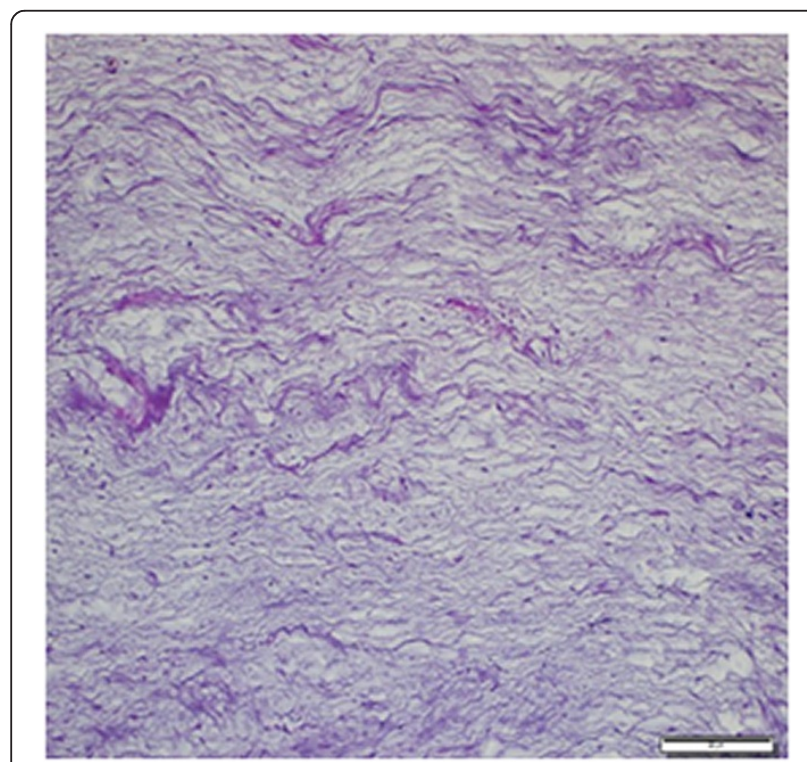

Figure 2 Tumor lesion with a small number of spindle or stellate cells, a small number of vessels, and abundant thin collagen fibers (hematoxylin and eosin $\times 100$ ). extensions. Cellular pleomorphism, cellularity and vascularity were low. There was no mitosis, necrosis or cystic degeneration. At the periphery of the lesion, the skeletal muscle adjacent to the tumor was atrophic with interspersed edema fluid or infiltrated tumor cells (Figures 3 and 4).

An immunohistochemical examination of the mass showed diffuse positivity for vimentin in tumor cells (Figure 5), focal and weak positivity for CD34 in peripheral regions and was negative for S-100. The Ki-67 proliferation index was less than $1 \%$. In the light of pathological data obtained, the mass was concluded to be intramuscular myxoma (Figure 6).

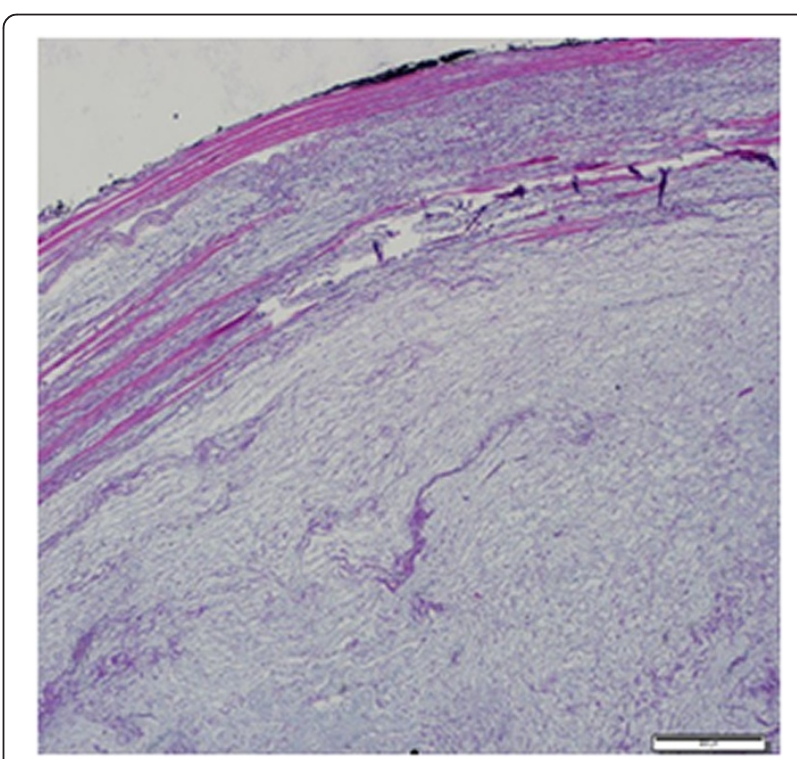

Figure 3 At the periphery of the lesion, the skeletal muscle adjacent to the tumor is atrophic. Tumor infiltration of muscle fibers can be monitored (hematoxylin and eosin $\times 200$ ). 


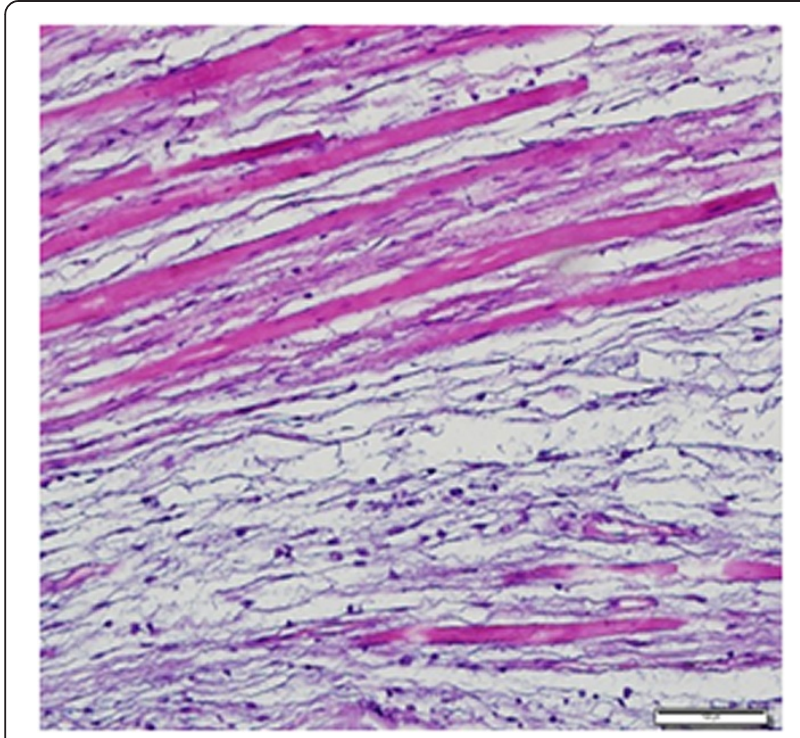

Figure 4 Appearance of the infiltrating tumor with atrophic surrounding muscle fibers at higher magnification.

\section{Discussion}

Myxoma is a benign soft tissue tumor of unknown origin [1]. It may originate from fibroblasts that are insufficiently differentiated and thus unable to synthesize collagen or it may originate from mesenchymal stem cells $[9,14]$. It was first described by Virchow in 1863 as a benign tumor similar to mucous tissue of the umbilical cord [15]. It was described as a mesenchymal neoplasm composed of undifferentiated stellate cells embedded in myxoid stroma containing weak reticular fibers in 1948 by Stout [1]. The etiology of myxomas remains elusive.

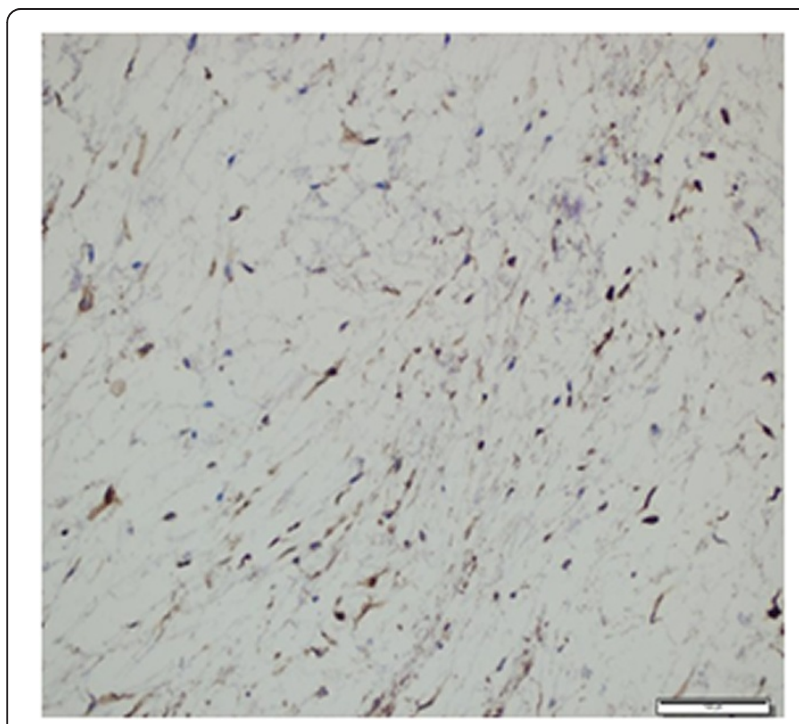

Figure $\mathbf{5}$ Immunohistochemical positivity in tumor cells (vimentin $\times 200$ ).

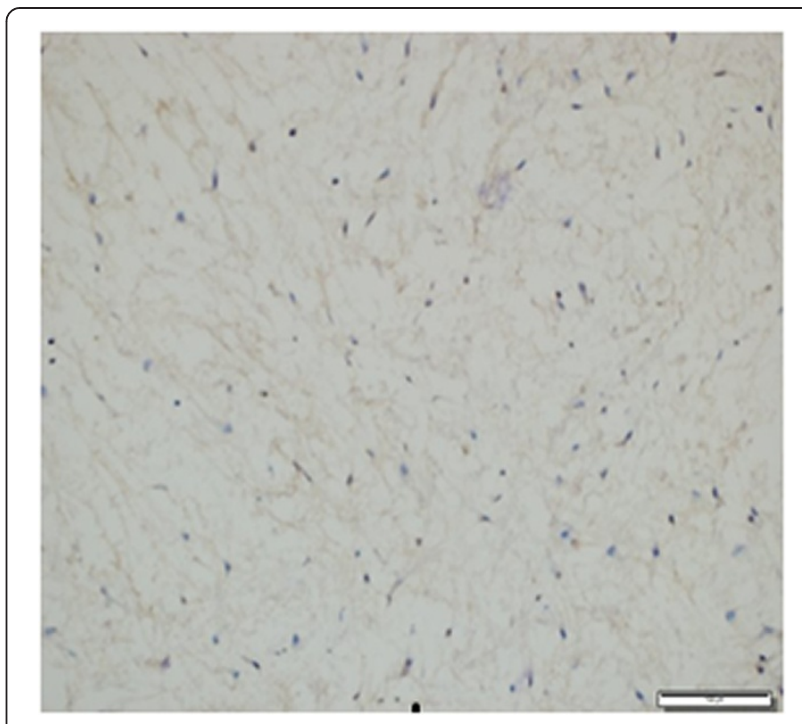

Figure 6 Immunohistochemical Ki-67 proliferation index is less than $1 \%$ in tumor cells $(\mathrm{Ki}-67 \times 200)$.

Some authors suggest that the etiology of myxomas may be traumatic [16]. One of the theories on their etiology is the growth of polysaccharide-producing cells in the neoplastic process $[8,16,17]$.

Soft tissue myxomas are rare [1]. Extracardiac myxomas most commonly occur in the head and skin tissue. Enzinger, in 1965, identified characteristic properties of a myxoma removed from intramuscular tissue, and described it as intramuscular myxoma [8].

Intramuscular myxomas can occur in the muscles of the thigh, buttocks, shoulder and upper extremities [9]. Intramuscular myxomas primarily affect patients between 40 and 70 years of age, with female predominance [4-7]. They usually follow an asymptomatic course and the most common clinical finding is a slow growing mass $[4,6-8,16,18]$. In the presence of an association of multiple intramuscular myxomas with fibrous dysplasia, Mazabraud syndrome (multiple intramuscular myxomas and fibrous dysplasia) or McCune-Albright syndrome (multiple intramuscular myxomas and polyostotic fibrous dysplasia, café-au-lait stains, endocrine hyperfunction) should be considered [2,9-14,19-22]. The case presented here had a single myxoma with no bone pathology.

On clinical examination, intramuscular myxoma presents as a painless, palpable mass. The clinical pattern varies depending on the size and site of the mass [14,23].

A radiograph reveals a nonspecific mass with no calcification. On ultrasonography, it appears as cystic lesions with echogenicity in normal muscle tissue [24]. On computed tomography, it has a homogenous appearance separating from the muscle tissue, similar to that of a cyst or low density mass [25]. The most important radiologic examination used for the mass is MRI. Intramuscular 
myxoma appears as a hypointense homogeneous mass on T1-weighted sections, and as a hyperintense mass on T2-weighted sections [2,25-29]. Fat-suppressed T2 sections demonstrate increased signal intensity associated with the increased water content of myxoid matrix [25]. Increased intensity can be detected around the mass resembling fat on T1-weighted sections. On T2weighted sections, edema is observed in the surrounding muscle tissue $[2,25,26]$. These MRI findings may be confused with other fluid-containing lesions such as myxoid sarcoma, hematoma, lymph nodes, cystic hygroma, cystic teratoma and abscess. The case presented here had a lobular contoured mass lesion, cystic in nature in the deltoid muscle. There was interstitial edema in the surrounding tissue. Other possible lesions were borne in mind in the differential diagnosis.

The differential diagnosis of intramuscular myxoma includes other myxoid neoplasms and proliferative lesions of the soft tissue [6]. Benign lesions such as myxolipoma, myxoid neurofibroma, neurothecoma, myxochondroma and nodular fasciitis and different types of low grade myxoid sarcomas should also be considered. Among them, the differential diagnosis should be established with low grade myxofibrosarcoma, myxoid liposarcoma, extraskeletal myxoid chondrosarcoma and low grade fibromyxoid sarcomas $[6,9,14]$.

Initial diagnosis can be checked by needle biopsy $[7,24]$ whereas several authors use intraoperative frozen section [30]. Differential diagnosis with benign lesions can be easily made by histological examination whereas it is difficult to make differential diagnosis by imaging techniques due to myxoid stroma inside myxomas [31]. In our case, an excisional biopsy was planned and the mass was excised at the surgical margin and a histopathological examination was performed.

There are transition zones between hypocellular myxoid areas and fat tissues in myxolipoma. Myxoid liposarcoma includes atypical lipoblasts and characteristic diffuse plexiform capillary network. Myxomas do not contain lipoblasts and have poor vascularity. Myxolipomas and liposarcomas stain positive for S-100 [19].

Neurofibroma cells display a greater degree of orientation whereas the vascularity is more prominent and they contain abundant collagen fibers. Some areas show positive staining for S-100. Neurothecomas contain prominent lobules separated by fibrous bands. Lobules consist of myxoid and cellular areas and stain positive for S-100 [19].

Myxochondromas contain lobular patterns with more cellular chondroid cell groups among myxoid areas, which usually stain positive for S-100. Myxoid chondrosarcomas present more pleomorphic, cellular and infiltrative growth [19].

Nodular fasciitis stains positive for smooth muscle. In myxomas, there is zonal organization or regional heterogeneity of nodular fasciitis. Myxomas are more hypocellular and have poor vascularity [19].

Low grade myxofibrosarcomas differ from myxomas in being more pleomorphic and ill defined, and in having a characteristic nodular pattern and organized vascular pattern. Low grade fibromyxoid sarcomas are characterized by contrasting myxoid and cellular fibrous areas with a swirling, whorled pattern [19].

Treatment of solitary myxomas is marginal surgical excision [7,9,32]. Extensive surgical resection is recommended by some surgeons [23]. No metastasis, recurrence or malignant change has been reported with this surgical procedure. However, recurrence has been reported in a small number of patients undergoing enucleation and incomplete resection [6,33]. Recurrent myxoma with atypical localization has been reported in patients with the association of Mazabraud syndrome and McCune-Albright syndrome [2,11,34,35].

In our case, no needle biopsy was performed and the entire mass was removed with wide margins along with the surrounding muscle tissue and the surgical specimen was sent for pathological examination. Histopathological examination revealed intramuscular myxoma. The patient's treatment was completed with extensive surgical excision in one session. Currently, she is at the postoperative 6-month follow-up with no complaints or recurrence.

\section{Conclusions}

In conclusion, intramuscular myxoma of the deltoid muscle is a very rare benign tumor. Even though imaging techniques are helpful, the exact diagnosis is established by histological examination. In the differential diagnosis, reactive lesions, myxoid nodular fasciitis and low grade myxoid sarcomas should be kept in mind, upon which the treatment should be planned.

\section{Consent}

Written informed consent was obtained from the patient for publication of this case report and accompanying images. A copy of the written consent is available for review by the Editor-in-Chief of this journal.

\section{Abbreviations}

MRI: Magnetic resonance imaging.

\section{Competing interests}

The authors declare that they have no competing interests.

\section{Authors' contributions}

$\mathrm{KO}$ and SM contributed to the conception and design of the study, carried out the literature research, manuscript preparation and manuscript review. BC and SS performed the histological examination of the mass. BK and MSS were involved with the case and writing of the manuscript, general management of the patient and revised the manuscript for important intellectual content. All authors read and approved the final manuscript.

Acknowledgement

No funding has been received for this study. 


\section{Author details}

'Orthopaedics and Traumatology Department, İ. Medeniyet University Göztepe Training and Research Hospital, İstanbul, Turkey. ${ }^{2}$ Pathology Department, I. Medeniyet University Göztepe Training and Research Hospital, Istanbul, Turkey. ${ }^{3}$ Orthopaedics and Traumatology Department, I. Kanuni Sultan Suleyman Training and Research Hospital, İstanbul, Turkey. ${ }^{4}$ Orthopaedics and Traumatology Department, İ. Medeniyet University, İstanbul, Turkey.

\section{Received: 8 May 2014 Accepted: 27 October 2014}

Published: 18 December 2014

\section{References}

1. Stout A: Myxoma: The tumor of primitive mesenchyme. Ann Surg 1948, 127:706-719.

2. Luna A, Martinez S, Bossen E: Magnetic resonance imaging of intramuscular myxoma with histological comparison and a review of the literature. Skeletal Radiol 2005, 34:19-28.

3. Abu Hassan FO: Extragnathic fibromyxoma of the calcaneum: report of a case. Foot Ankle Surg 2002, 8:59-62.

4. Kindblom LG, Stener B, Angervall L: Intramuscular myxoma. Cancer 1974, 34:1737-1744

5. Miettinen M, Hockerstedt K, Reitamo J, Totterman S: Intramuscular myxoma: a clinicopathological study of twenty-three cases. Am J Clin Pathol 1985, 84:265-272.

6. Nielsen GP, O'Connell JX, Rosenberg AE: Intramuscular myxoma: a clinicopathologic study of 51 cases with emphasis on hypercellular and hypervascular variants. Am J Surg Pathol 1998, 22:1222-1227.

7. Silver WP, Harrelson JM, Scully SP: Intramuscular myxoma: a clinicopathologic study of 17 patients. Clin Orthop Relat Res 2002, 403:191-197.

8. Enzinger FM: Intramuscular myxoma; a review and follow-up study of 34 cases. Am J Clin Pathol 1965, 43:104-113.

9. Allen PW: Myxoma is not a single entity: a review of the concept of myxoma. Ann Diagn Pathol 2000, 4:99-123.

10. Blasier RD, Ryan JR, Schaldenbrand MF: Multiple myxomata of soft tissue associated with polyostotic fibrous dysplasia: a case report. Clin Orthop Relat Res 1986, 206:211-214.

11. Iwasko N, Steinbach LS, Disler D, Pathria M, Hottya GA, Kattapuram S, Varma $D G$, Kumar R: Imaging findings in Mazabraud's syndrome: seven new cases. Skeletal Radiol 2002, 31:81-87.

12. Szendroi M, Rahoty P, Antal I, Kiss J: Fibrous dysplasia associated with intramuscular myxoma (Mazabraud's syndrome): a long-term follow-up of three cases. J Cancer Res Clin Oncol 1998, 124:401-406.

13. Wirth WA, Leavitt D, Enzinger FM: Multiple intramuscular myxomas: another extraskeletal manifestation of fibrous dysplasia. Cancer 1971, 27:1167-1173

14. Van Roggen JGF, McMenamin ME, Fletcher CDM: Cellular myxoma of soft tissue: a clinicopathological study of 38 cases confirming indolent clinical behaviour. Histopathology 2001, 39:287-297.

15. Virchow R: Cellular Pathology as Based upon Physiological and Pathological Histology. Philadelphia: JB Lippincott: 1863:525-526.

16. Hashimoto H, Tsuneyoshi M, Daimaru Y, Enjoji M, Shinohara N: Intramuscular myxoma: a clinicopathologic, immunohistochemical, and electron microscopic study. Cancer 1986, 58:740-747.

17. Ireland DC, Soule EH, Ivins JC: Myxoma of somatic soft tissues: a report of 58 patients, 3 with multiple tumors and fibrous dysplasia of bone. Mayo Clin Proc 1973, 48:401-410.

18. Caraway NP, Staerkel GA, Fanning CV, Varma DG, Pollock RE: Diagnosing intramuscular myxoma by fine-needle aspiration: a multidisciplinary approach. Diagn Cytopathol 1994, 11:255-261.

19. Weiss SW, Goldblum JR: Enzinger Weiss's soft tissue tumors, Intromuscular myxoma. 4th edition. St. Louis: Mosby Inc; 2001:1425-1436.

20. Dormand EL, Prabhu-Desai A, Rice AJ, Rosin RD: Not all pain in the left iliac fossa is diverticular disease: a case study of a psoas myxoma and review. Surgeon 2006, 4:239-243.

21. Macfarlane P, Lew W, Neuhaus S: An aggressive case of Mazabraud's syndrome. Eur J Surg Oncol 2007, 33:1087-1089.

22. Endo M, Kawai A, Kobayashi E, Morimoto Y, Yamaguchi U, Nakatani F, Chuman H, Seki K, Beppu Y: Solitary intramuscular myxoma with monostotic fibrous dysplasia as a rare variant of Mazabraud's syndrome. Skeletal Radiol 2007, 36:523-529.

23. Charron P, Smith J: Intramuscular myxomas: a clinicopathologic study with emphasis on surgical management. Am Surg 2004, 70:1073-1077.

24. Liu JC, Chiou HJ, Chen WM, Chou YH, Chen TH, Chen W, Yen CC, Chiu SY, Chang CY: Sonographically guided core needle biopsy of soft tissue neoplasms. J Clin Ultrasound 2004, 32(6):294-298.

25. Murphey MD, McRae GA, Fanburg-Smith JC, Temple HT, Levine AM, Aboulafia AJ: Imaging of soft-tissue myxoma with emphasis on CT and $\mathrm{MR}$ and comparison of radiologic and pathologic findings. Radiology 2002, 225:215-224

26. Bancroft LW, Kransdorf MJ, Menke DM, O'Connor MI, Foster WC: Intramuscular myxoma: characteristic MR imaging features. AJR Am J Roentgenol 2002, 178:1255-1259.

27. Nishimoto K, Kusuzaki K, Matsumine A, Seto M, Fukutome K, Maeda M, Hosoi S, Uchida A: Surrounding muscle edema detected by MRI is valuable for diagnosis of intramuscular myxoma. Oncol Rep 2004, 11:143-148.

28. Peterson KK, Renfrew DL, Feddersen RM, Buckwalter JA, El-Khoury GY: Magnetic resonance imaging of myxoid containing tumors. Skeletal Radiol 1991, 20:245-250.

29. Abdelwahab AF, Kenan S, Hermann G, Lewis MM, Klein MJ: Intramuscular myxoma: magnetic resonance features. Br J Radiol 1992, 65:485-490.

30. Darlis NA, Korompilias AV, Skopelitou AS, Petropoulou KA, Soucacos PN: Soft tissue mass in the proximal forearm of a 17-year-old girl. Clin Orthop Relat Res 2005, 437:265-270.

31. van Roggen JFG, Hogendoorn PC, Fletcher CD: Myxoid tumours of soft tissue. Histopathology 1999, 35:291-312.

32. Winke BM, Blair WF, Benda JA: Myxomas in the finger tips. Clin Orthop 1988, 237:271-273

33. Orlandi A, Bianchi L, Marino B, Spagnoli LG, Nini G: Intramuscular myxoma of the face: an unusual localization. A clinicopathological study. Dermatol Surg 1995, 21:251-254

34. Gober GA, Nicholas RW: Case report 800: Skeletal fibrous dysplasia associated with intramuscular myxoma (Mazabraud's syndrome). Skeletal Radiol 1993, 22:452-455.

35. Fletcher JW, Watson HK, Weinzweig J: Recurrent myxoma of the hand. $J$ Hand Surg Am 2000, 25:772-775.

doi:10.1186/1752-1947-8-441

Cite this article as: Kemah et al:: A case of intramuscular myxoma presenting as a swollen shoulder: a case report. Journal of Medical Case Reports 2014 8:441.

\section{Submit your next manuscript to BioMed Central and take full advantage of:}

- Convenient online submission

- Thorough peer review

- No space constraints or color figure charges

- Immediate publication on acceptance

- Inclusion in PubMed, CAS, Scopus and Google Scholar

- Research which is freely available for redistribution 